\title{
Survey, Research And Prospect Of Signage Systems In National Parks In Yunnan Province
}

\author{
XU wenjuan ${ }^{1, a}$ and FAN shengxi ${ }^{2}$ \\ ${ }^{1}$ Department of Architecture and Urban Planning, Tongji University, 200092 No. 1239, Siping Road, Shanghai, \\ College of Art and Design, sanda University, Shanghai \\ ${ }^{2}$ College of Design and Innovation, Tongji University, 200092 No. 1239, Siping Road, Shanghai
}

\begin{abstract}
The Signage System is essential to establishing a national park, The authors conducted surveys, analysis and research of identification signs, informational sign, directional signs and functional signs from the signage systems adopted by five national parks in Yunnan Province. Relying on the results, with reference to industry experience, years of research related to national park, successful cases of overseas national parks and the current signage systems across China's national parks, the paper aims to explore future development strategies of national park signage systems that are suitable for China.
\end{abstract}

\section{Introduction}

National parks are established to conserve the most characteristic, valuable, representative natural and cultural landscapes and ecological systems in a country [1]. In a way, they are regarded as national symbols. The signage system is the direct manifestation of how well a national park is established and managed and an important part of its brand identification and promotion.

Started late in building national parks, China is still exploring and developing national park management systems, policies, and laws and regulations [2]. The authors carried out surveys and analysis of five pilot national parks in Yunnan Province and developed the design principles, guidelines and evaluation models for the signage system used in China's national parks, thereby making contribution to creating a distinctive national park image and facilitating development of national park systems and policies.

\section{Surveys on Signage Systems in Yunnan's National Parks}

\subsection{Overview}

\subsubsection{Purpose}

From the perspective of the national parks' brand-building efforts, the survey, analysis and research focused on various categories of signs, such as identification signs, directional signs and functional

a Corresponding author: 34425965@qq.com 
signs, from the signage systems adopted by the national parks in Yunnan Province. The ultimate goal is to explore strategies and roadmaps to systematically develop the national park signage systems that suite China's situation.

\subsubsection{Survey Methods}

(1) Observation: This is a non-participating survey approach. The observation activities for this survey were divided into two categories. First, all signs in the parks were catalogued, photographed and sorted. Second, by following the tourists visiting the parks, the researchers observed and objectively recorded all their activities and conversations from the point when they arrived at the parks to the point when they left, down to details such as when and where they stopped, made turns, looked for directions, tried to find ways and asked for information [3].

(2) Interview: Executives of the management companies in charge of the five national parks were interviewed to gather information about the pilot signage systems in the parks.

(3) Experiment: One respondent was selected at every point of observation to carry out the specified tour tasks as planned. The respondents were asked to find ways using the signs currently in use in the parks. All their activities and experience were objectively recorded.

\subsection{Implementation}

\subsubsection{Highway Traffic Signs}

The first two stops were Podatso National Park and Meili Snow Mountain National Park, The researchers drove from Lijiang City to the parks and observed the signage systems along the way. Both the national highways and the provincial highways have complete and well-rounded signage systems, including traffic signs, scenic site signs, warning signs, prohibitive signs, instructional signs, directional signs, road construction and safety signs, and other signs, with comprehensive coverage and explicit directions. Particularly, the signs for Meili Snow Mountain, Podatso, White Horse Snow Mountain, and other scenic sites were placed at intervals along the national highway and clearly indicate the direction and distance to the destinations. Besides, noticeable billboards were usually erected 5 kilometers away from the scenic spots for the publicity purpose.

The third stop was Laojun Mountain National Park in Lijiang. From the interviews with related park management executives, it developed and built a signage system by itself, rather than using the standard signage system from the Tourism Administration Bureau of Yunnan Province. Due to limited funding, the signage designs fell short in many aspects, from styles, sizes, materials and visual effects, to reasonable distribution, quantity and design expertise. In addition, the scenic site signs along the way to the national park, used the name "Lijiang Laojun Mountain Liming Scenic Zone", without mentioning its national park status. Evidently, after being titled as a national park, Laojun Mountain had not re-planned and re-designed its signs in the scenic spot.

Xishuangbanna Tropical Rain Forest National Park's Parashorea Scenic Zone was the last stop. The scenic site signs in remote regions of the prefecture and different districts of the tropical rain forest national park were not comprehensive and widely distributed. The travel almost entirely relied on the navigation system. Although there were scenic site signs along the way indicating there was a tropical rain forest national park, they did not indicate which districts were nearby. Tourists had to ask the national park staff members for more information. Parashorea Scenic Zone is situated in a remote county, Mengla, with harsh road conditions and underdeveloped traffic. Without sufficient guidance of scenic site signs, the researchers took wrong ways from time to time, even assisted by the navigation system. 


\section{(1) Podatso National Park}

Podatso is the first pilot national park established in Mainland China upon approval by China's State Forestry Administration [4]. At the time of the survey, the Tourist Service Center was under reconstruction. However, tourists visiting the park still could use the comprehensive signage system. The signs for different facilities, such as parking lots, the Tourist Service Center and different businesses in the park, were well distributed and structured. Tourists can choose the single-direction route or the destination-specific routes. There were a great variety of the signs, such as the identification signs at the entrances, informational signs, directional signs, and functional signs. Meanwhile, the signs were widely and sufficiently distributed. To facilitate on-going maintenance and easy locating, every informational sign was numbered, helping tourists easily locate themselves and find ways in the park and staff members maintain the signs. Podatso National Park has a reasonable overall planning and design of the in-park signage system. But still, across the park there was no sign set up for fire fighting safety and related facilities.

(2) Meili Snow Mountain National Park

Each zone in Meili Snow Mountain National Park covers a large area and has a well-planned and reasonably-organized signage system. as the examples in Figure 1, did an outstanding work in narrating the culture of Meili Snow Mountain. Along the hiking trail in Meili Snow Mountain, there were rest facilities and directional signs at one-kilometer interval, and serial numbers and altitudes were marked on the electric poles.

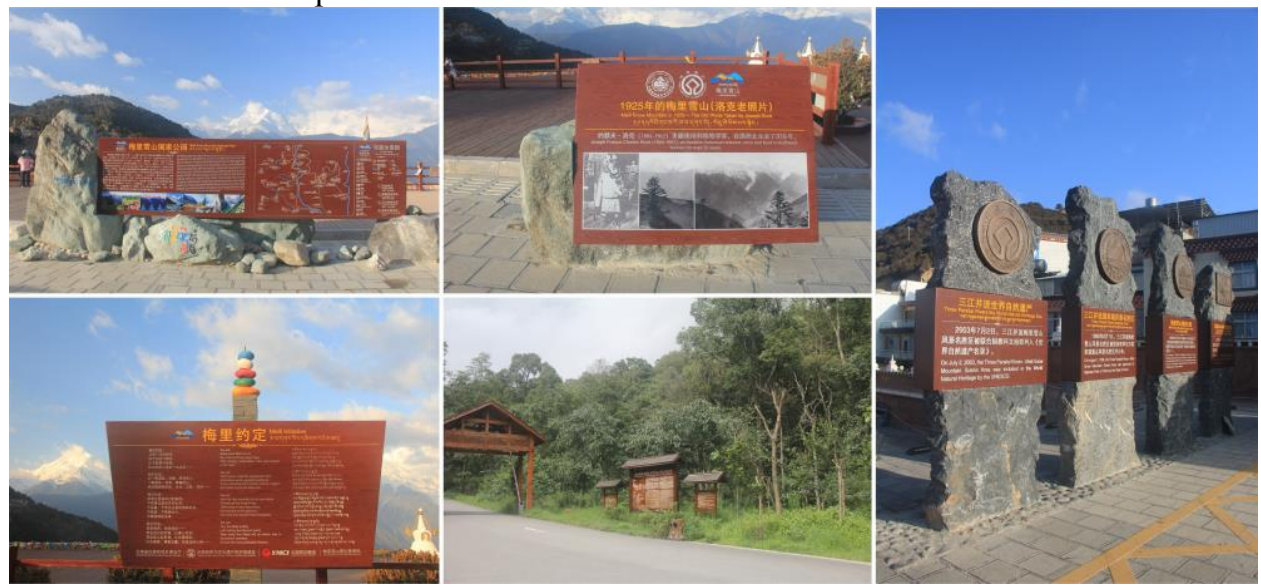

Figure 1. The signage system in Meili Snow Mountain National Park

(3) Laojun Mountain National Park and Xishuangbanna Tropical Rain Forest National Park

In Laojun Mountain National Park, the cultural promotion and park management were quite obsolete. The identification sign at the park's entrance still showed the former name, "Liming Scenic Site, a Key National Scenery Area for Three Parallel Rivers". Inside the park, the identification signs indicated that the park was "Laojun Mountain Geological Park", without any text or logo about its national park status. The in-park signage system used two distinct logos for the park. Identification signs were not consistent and introduced the park as "geological park", "famous scenery area", "World Heritage", or "national park". The park's logo was not consistent in design: some were using three symbols, and some were four patterns with a national park mark.

Signs of the tourist service center at Parashorea Scenic Zone, Xishuangbanna Tropical Rain Forest National Park only showed its name "Parashorea Scenic Zone" and indicated that the park was a "famous state scenery area", without any mention of its national park status. Riding a boat into the scenic zone, the researchers saw bulletin boards that showed the text "tropical rain forest national park" and identification signs in the zone. However, such signs were not placed at the entrance. Generally speaking, the zone mostly used its original out-of-date signage system.

(4) Pu'er National Park 
Reconstruction of Pu'er National Park was approved in 2011 and it reopened to the public in 2013. However, the park lacks consistency in naming, as it now uses two names, Pu'er National Park and Pu'er Sun River National Park. Its Xiniuping Scenic Site did not have any sign to indicate its national park status at the time of the survey, its signage system underwent re-planning and re-construction as part of its overall planning efforts after gained the national park title. The signs and facilities were considerate, reasonably planned, well designed, and fully functional, perfectly fitted into the park environment.

\section{Survey Results and Analysis}

On the basis of the survey and analysis of the five pilot national parks in Yunnan Province, it can be concluded that the signage systems in China's national parks vary in maturity: some are well planned, while other remain underdeveloped. In this case, planning and design of the overall signage systems in Podatso National Park and Meili Snow Mountain National Park are relatively complete and comprehensive. In comparison, Laojun Mountain National Park, Xishuangbanna Tropical Rain Forest National Park and Pu'er National Park mostly made some adjustments to their existing scenic spot signage systems and come short of consistent management, guidelines and standards.

\subsection{Naming of National Park}

Every one of the five national parks in this survey was named differently, even the same national park uses distinct names in different places. There is no standard naming approach.

\subsection{Out-of-park Signs and Support Information}

The out-of-park signs and support information mainly refer to the traffic signs, scenic site signs, warning signs, prohibitive signs, instructional signs, directional signs, road construction safety signs, secondary signs and billboards. Planning of the signs and support information reflects primarily the overall management of a national park, and can directly impact tourists' visual perception and psychological feeling [5].

\subsection{In-park Signage Systems}

The survey results show that Podatso National Park and Meili Snow Mountain National Park were pilot parks established earlier than others and the planning and design of their signage systems were reasonable and widely distributed. Laojun Mountain National Park and Xishuangbanna Tropical Rain Forest National Park were using their existing signage systems with some adjustments and additions, and there was information inconsistency in some aspects. Pu'er National Park's signage system, after it gained its national park status, underwent reasonable planning and design as a whole. Table 1 analyzes the in-park signs of the five national parks.

Table 1. In-park Signage Systems of the five National Parks

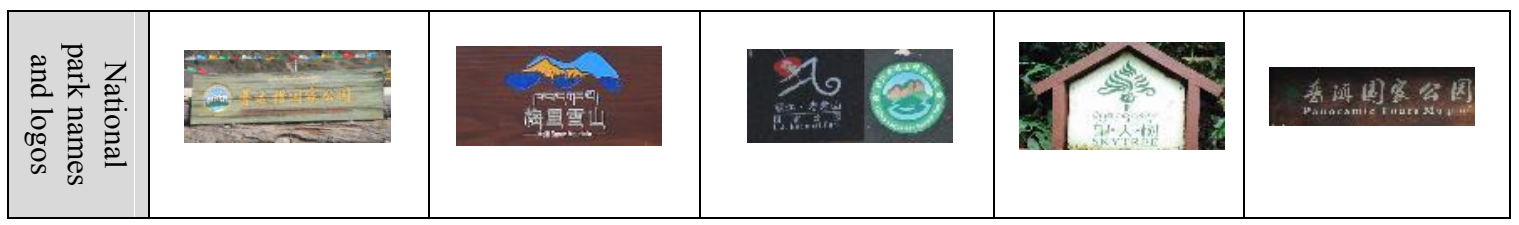




\begin{tabular}{|c|c|c|c|c|c|}
\hline 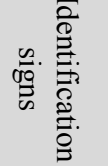 & $5=-\frac{2}{2}$ & $\begin{array}{l}\text { No identification } \\
\text { signs }\end{array}$ & $\begin{array}{l}\text { No identification } \\
\text { signs }\end{array}$ & & 627 \\
\hline 志 & $\left.\right|_{1} ^{1}-\left.\right|^{2}$ & $17 x+4$ & & & $8=-4$ \\
\hline 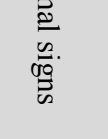 & $\begin{array}{l}\text { No general index, } \\
\text { but the regional } \\
\text { index is numbered }\end{array}$ & $\begin{array}{l}\text { General index } \\
\text { Regional index }\end{array}$ & $\begin{array}{l}\text { Both information } \\
\text { signs and } \\
\text { informational signs }\end{array}$ & General index & $\begin{array}{l}\text { General index } \\
\text { Regional index }\end{array}$ \\
\hline 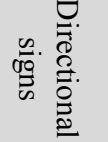 & & 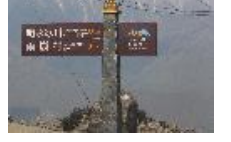 & & & $\begin{array}{l}\text { One-direction } \\
\text { tour route, no } \\
\text { directional signs }\end{array}$ \\
\hline 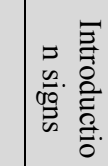 & & nes & & & 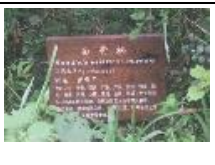 \\
\hline 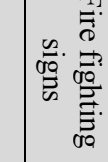 & No such signs & No such signs; & No such signs; & No such signs; & $\begin{array}{l}\text { No such signs; } \\
\text { only fire }\end{array}$ \\
\hline 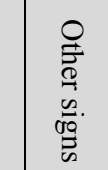 & & 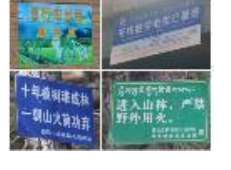 & attac & $\begin{array}{l}1 \\
4\end{array}$ & 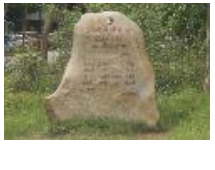 \\
\hline
\end{tabular}

\section{Long Way ahead in Developing China's National Park Signage System}

New hope is born out of pains, and transition comes with confusion. The first national parks in China are challenged in every way. There is still a long way ahead to develop and mature China's signage systems. On the basis of industry experience in signage design, years of research related to national parks, successful cases of signage systems in overseas national parks, and the current situation of signage systems in China's national parks, the authors put forward a few ideas about future development of the systems in China.

\subsection{National Park Naming}

When it comes to brand building, national parks first need to develop and follow standard naming conventions or fixed name structures, such as "Provincial name + City name + Park name + National 
Park", or "Park name + National Park", or other structures. A national park must use one name and keep it consistent for various purposes, such as signs, advertisements, tickets and websites.

\subsection{Develop a Visual Identification System for China's National Park Brands}

China has to establish standards and regulations on planning and design of a VI (visual identity) system for national parks, including logos, standard fonts, standard colors, supporting graphics, mascots, and so on. Various VI systems, particularly signage system, must remain consistent when being used for different purposes.

\subsection{Principles and Rules of Signage Design}

The signage system is a complete and independent system. In the same way, China's national parks also need separate principles and standards to guide planning and design of the signage system.

\subsubsection{Graphical design standards}

Develop and implement the Standards of Public Information Graphics and Symbols for National Parks in China, to meet the specific needs of national parks.

\subsubsection{Out-of-part road signs}

Standardize the out-of-park scenic site signs along the highways and road that lead to the national parks. The parks can choose to continue using their existing road sign standards, or further develop and adjust the old standards, which should cover interval distance, dimensions, materials, colors, and so on. The design and location of billboards also should follow related standards, such as sizes, advertising messages, and locations.

\subsubsection{Design standards on sign categories (specific design standards for every category of signs)}

The signs should be primarily categorized by functions, such as identification signs, informational signs, directional signs and functional signs.

\subsubsection{Other signage systems}

When adopting new categories of signs, like touch-sensitive signs, auditory signs, and induction signs, national parks should follow the specific design guidelines and design standards.

\subsubsection{Sign making and installation standards}

Sign making and installation should follow related national and industry standards.

\section{References}

1. Forest Park Administration Office of State Forestry Administration, Central South University of Forestry and Technology, Comparative Study of National Park Systems [M], Beijing: China Forestry Press, 2015:8-9.

2. LI Rusheng, Administration Systems of American National Parks [M], Beijing: China Architecture and Building Press, 2005.

3. National Park Service. (2008). The National Park Service Organic Act. 
4. Tourism research and planning center of Peking University, Tourism Planning \& Design [J], Beijing: China Architecture and Building Press, 2005.

5. WANG Mo, Study of Establishing Scenic Site Signage Systems [J], Chinese Landscape Architecture, 2013, 12 (2):38-42. 